\title{
Challenges Confronted by Korean Students in a Chinese University: An Interview Study
}

\author{
Ying $\mathrm{Li}^{1} \&$ Meihua $\mathrm{Liu}^{2}$ \\ ${ }^{1}$ Institute of Education, Tsinghua University, Beijing, China \\ ${ }^{2}$ Department of Foreign Language and Literatures, Tsinghua University, Beijing, China \\ Correspondence: Meihua Liu, Department of Foreign Language and Literatures, Tsinghua University, Beijing, \\ 100084, China. E-mail: ellenlmh@yahoo.com
}

\author{
Received: February 24, 2015 Accepted: April 20, 2015 Online Published: June 29, 2015 \\ doi:10.5539/elt.v8n7p216 URL: http://dx.doi.org/10.5539/elt.v8n7p216
}

\begin{abstract}
During recent decades, both institutions of higher education and university students of the world are trying to become international by offering or gaining some form of international education, which has caught the attention of increasingly more researchers (Jackson, 2004; Trenchs-Parera, 2009). As East Asian students have increasingly become the majority of international students on university campuses (Xia, 2009), Chinese institutions of higher education have also been recruiting more and more international students. Nevertheless, research on international students in China has been scarce. The present interview study aimed to document the challenges Korean students had while studying full-time in a prestigious university in Beijing. Interviews with 10 senior Korean English majors revealed that they confronted a series of academic, linguistic and cultural challenges while studying in the university. Based on this finding, some implications are discussed.
\end{abstract}

Keywords: interview study, academic, linguistic, cultural

\section{Introduction}

During recent decades, both institutions of higher education and university students of the world are trying to become international by offering or gaining some form of international education (Jackson, 2004; Trenchs-Parera, 2009). As East Asian students have increasingly become the majority of international students on university campuses (Xia, 2009), Chinese institutions of higher education have also been recruiting more and more international students. In Mainland China, the number of international students who come to study in China for varying lengths of time has been increasing all the years, among which Korean students account for the largest percentage. Nevertheless, research on international students in China has been scarce. The present study aims to document the challenges Korean students had while studying full-time in a prestigious university in Beijing.

\section{Literature Review}

Studying abroad (SA) is the act of pursuing educational opportunities in a country other than one's own. As more and more students and institutions of higher education become interested in SA, an array of research has been done on SA. Most research has shown SA programs to be facilitative in acquiring the second language skills (i.e., listening, reading, speaking and writing) (Cai, Li, \& Liu, 2013; Chen, 2007; Hernández, 2010; Lafford, 2004; Lindseth, 2010; Pérez-Vidal \& Juan-Garau, 2011; Taguchi, 2008; Taillefer, 2005) as well as intercultural competence (Batalle, 2010; Cohen \& Shively, 2007; Jackson, 2011; Martinsen, 2011; Xu, Case, \& Wang, 2009). It has been claimed that students abroad become significantly more fluent (Lafford, 2004; Segalowitz \& Freed, 2004) and significantly increase their vocabulary after their experience in the foreign country (Dewey, 2008; Llanes \& Muñoz, 2009; Milton \& Meara, 1995). For example, when investigating the changes in English writing behavior between 7 SA students and 6 at-home students, Sasaki (2007) found that only SA students improved their second language writing ability and fluency, that they made more local plans, and that they became more motivated to write better compositions in the target language. These findings were supported by subsequent research (Allen, 2010; Pérez-Vidal \& Juan-Garau, 2011).

Probably because too much research focuses on the positive effects of SA on sojourners' linguistic, academic and intercultural competence, very few studies have explored sojourners' concerns, difficulties, and challenges 
while abroad. Even so, some research did so (Berry \& Williams, 2004; Koester, 1986; Liu \& Cai, 2013; Wilkinson, 1998a, 1998b). For example, Wilkinson (1998a) found that the students suffered from 'stranger anxiety' during SA which might increase their reliance on their home culture. Berry and Williams' (2004) study of 20 Hong Kong Chinese learners aged 12-18 studying in an English-peaking country found that the sojourners suffered not only language problems but socio-cultural (e.g., cultural difference, differences in the school systems and school culture, etc.), and affective (e.g., anxiety, pressure from English and Chinese peers, etc.) problems. Nagy (2008) studied 10 Hungarian undergraduates' socio-cultural and linguistic experiences in the UK. The results showed that the students found it difficult to become intimate friends with the locals. Wilkinson's (1998b) longitudinal study of four American students who spent 1month in France found that the root of many cross-cultural communication problems stemmed from cultural instead of linguistic misunderstandings. The study also revealed that most respondents tended to band together when facing unexpected frustrations with cross-cultural contacts. The researcher thus claimed that deep cultural understanding could not be acquired if the participants chose to stick to their own culture when abroad, especially when differences occurred. Wilkinson (1998b) also found that sojourner adjustment tended to increase over time as the individual acquired culture-specific knowledge and learnt to deal with sociocultural and psychological stress, as found in Ward and Kennedy (1994). Liu and Cai (2013) collected data from 33 third-year Chinese undergraduate English majors who joined a semester-long exchange program in English-speaking countries via questionnaires and semi-structured interviews. They found that most participants had worries and concerns about their stay abroad such as culture shock, classroom participation, intercultural interaction, and language barrier. The researchers thus suggested that an orientation or program should be provided by the home university to prepare the students better for their study and life abroad prior to their sojourn.

As China becomes more powerful, increasingly more international students come to study in China in recent decades. According to the statistics issued by China's Ministry of Education, 328,330 and 356,499 international students studied in China in 2012 and 2013 respectively. Nevertheless, research on internationals studying in China is scarce, except that some researchers attempted to examine sojourners' attitudes towards China (Chen, 2007; Yang, 2012; Yu, 2010). Yang (2012) examined the image and knowledge of China emerging in mainstream discourse in USA and students' attitudes towards China who had spent a few months in China. The study found that the students' attitudes towards China and how the students interpreted their experiences in China were shaped by how China had been represented in the mainstream discourse in the United States, which was influenced by the ideological difference and power dynamics between the two countries. The study also revealed that the source of a message, the way a message was delivered and the students' related prior experience and knowledge all played an important role in the effectiveness of a message.

\section{Rationale for the Present Study}

As reviewed, most of the current SA studies are situated in English speaking countries or certain specific countries or regions such as Hong Kong, and Hungary. As more and more Chinese institutes of higher education and college students are involved in SA, research is urgently called for in this area to examine students' study and life during SA, such as how well they fit into the local life and community, how to prepare them to maximize their time abroad, and so on. It is the same with international students studying in Chinese institutes. Nevertheless, research on the issue is scarce, except that some researchers attempted to examine sojourners' attitudes towards China (Chen, 2007; Yang, 2012). And research on Korean students studying in China is even scarcer, who have been the largest number of (around 90\%) internationals in Chinese institutions of higher education in recent years, as shown by the statistics issued by China's Ministry of Education.

Despite that both Korea and China are located in East Asia and worship Confucianism, the cultures are much different in terms of living style, educational system, perception of the world, and so on. This means that Korean students may have difficulty adapting to the life and study of the host university while studying in China, which is exactly the focus of the present study.

\section{The Present Study}

\subsection{Participants}

Ten (nine females and one male) senior English-majors from Korea at a highly prestigious university in Beijing participated in the present study. With an age range of 21 to 24, all the interviewees had stayed in China for seven or eight years since they came to China in the $7^{\text {th }}$ or $11^{\text {th }}$ grade. Before coming to China, all the informants except two (Judy and Janice) had not studied any Chinese or were able to speak and read any Chinese. Meanwhile, Except Ada who had studied in America for 3 years, all the others had never studied abroad before 
coming to China. More information of the participants is presented in Table 1.

Table 1. Detailed information of the participants

\begin{tabular}{lllllll}
\hline & Gender & Age & $\begin{array}{l}\text { Whether having studied } \\
\text { in other countries before } \\
\text { coming to China }\end{array}$ & $\begin{array}{l}\text { Grade in which } \\
\text { they } \\
\text { China }\end{array}$ & $\begin{array}{l}\text { Time of learning } \\
\text { Chinese before }\end{array}$ & $\begin{array}{l}\text { Duration } \\
\text { staying of } \\
\text { coming to China } \\
\text { China (year) }\end{array}$ \\
\hline Cindy & Female & 23 & No & $9^{\text {th }}$ & 0 & 8 \\
Judy & Female & 23 & No & $10^{\text {th }}$ & 2 years & 7 \\
Jane & Female & 23 & No & $9^{\text {th }}$ & 0 & 8 \\
Janice & Female & 23 & No & $11^{\text {th }}$ & 1 year & 7 \\
Tim & Male & 23 & No & $9^{\text {th }}$ & 0 & 8 \\
Linda & Female & 21 & No & $7^{\text {th }}$ & 0 & 8 \\
Amy & Female & 23 & No & $8^{\text {th }}$ & 0 & 8 \\
Tara & Female & 22 & No & $10^{\text {th }}$ & 0 & 7 \\
Ellen & Female & 24 & No & $9^{\text {th }}$ & 0 & 7 \\
Ada & Female & 23 & 3 years in US & $8^{\text {th }}$ & 0 & 8 \\
\hline
\end{tabular}

All the participants had family members or relatives doing business in China and were encouraged or recommended by their parents to come to study in China, in addition to several other reasons. To Cindy and Judy, China "has become" or would be "the biggest trading partner of Korea", so learning Chinese and the Chinese culture was important. And Cindy believed that studying in China was the best way if Koreans wanted to learn about China. Judy held that being able to speak both English and Chinese would make it easy for her to get a job offer from a famous enterprise in her home country. Jane maintained that studying in China would be a great experience for her, which would be very different from studying in Korea. Linda believed that English had already become too common in Korea and that being able to speak Chinese would put her in advantage. Amy believed that studying in China was very valuable. Apart from these reasons, being close to Korea and cheaper to study in China than in other countries such as Japan and USA is another major reason for the participants to come to study in a Chinese university.

\subsection{Semi-Structured Interview}

In order to obtain insiders' views toward studying in China, all the 10 participants were invited for semi-structured interviews. The interview guide of the present study covered such questions as background information, academic/adaptation challenges, linguistic challenges, cultural challenges, coping strategies, and suggestions.

\subsection{Procedure}

All the interviews were conducted within one week $\left(11^{\text {th }}\right.$ week of the 16 -week term), each of which lasted 40 to 60 minutes. All the interviews were tape-recorded and conducted mainly in Chinese, with a mixture of English when the interviewees felt it necessary to switch to English.

\subsection{Data Analysis}

All the interview data were transcribed and double-checked, which was then subjected to open coding to identify recurrent themes and issues (Charmaz, 2006; Richards, 2009). All the sources were triangulated and pseudo names were used for the interviewees when presenting the results.

\section{Results and Discussion}

As found in the interviews, all the 10 informants lived alone or shared the dormitory with Korean students when studying in the Chinese university. During their almost 4 years on campus, they had encountered a series of academic, linguistic and cultural challenges, as detailed below. 


\subsection{Academic Challenges}

\subsubsection{Administration Challenges}

When asked about academic challenges at university, all the interviewees reported administration challenges they encountered in China. When they were still high school graduates and were trying to choose which university to go to and what discipline to be in, the high schools and agencies that were supposed to help them did not provide them with enough useful information. What they cared about more was the ranking of universities in China. To them, the more students were admitted into high-ranking universities, the better, without taking anything into account such as whether the students liked the university or the discipline. This, coupled with the fact that most international students were not much familiar with Chinese universities and how they worked at the time, offered the interviewees few choices about universities and disciplines.

After they came to the university, they realized that Korean students had separate classes with the local students, though they were all English majors, and were even taught by the same instructors. In addition, international students were not allowed to live with the local students either, instead, they had to live in residentials only for internationals if they chose to live on campus. All these were "very disappointing" (Rachel), because not living or studying with the locals meant that they were not studying abroad, and that they could not experience how Chinese students studied or lived in university.

Since they came to study in the university, either because the university did not provide the internationals with enough information or because they themselves did not take the initiative to access as much information as possible about the university, all the informants reported that they were not well-informed of the program requirement, curriculum, credit system, and other management systems, which were "very complicated" (Amy). Hence, they confided that they were not sure how many credits were required of them to finish the BA study, what courses were more competitive or challenging, what was expected of them by the university, and so on. In a word, 8 of the 10 interviewees felt they were isolated from the local community by the university's administration system.

As reported by the interviewees, little knowledge of the school's curriculum and managements systems caused most of the challenges confronted by Korean students. Facing this, 8 interviewees confided that they, as well as other Korean students, would turn to their superiors for help who had come to study in the university earlier.

\subsubsection{Academic Challenges}

As reported in the interviews, partly because they did not choose the university and/or the discipline on their own will, partly because they were not sure of the requirements of the university, and partly because they felt they were isolated from the local community by the university, the informants generally did not study hard. Nor were they motivated to study well. They did not "care about whether there are any (new) policies concerning local or international students issued by the university" (Tim) either. All these made the interviewees, or most Korean students, "passive learners" (Judy). To Janice, the university underestimated their ability in that the instructors were not demanding and the assignments were not challenging, which disappointed and demotivated her. Thus, as they recalled, most Korean students idled away their time during their first year on campus, and wasted much time in the following years as well.

In the few courses which Korean students could take with the local students, the informants reported that they were biased by the instructors. As they confided, instructors tended to discriminate Korean students, especially in politics-related courses. For example, Amy took a course about Communism, hoping to know more about China's political system which was different from her home country's. To her astonishment, when the instructor knew there was a Korean student in class, he started to criticize Korea. To most interviewees (8/80\%), it was natural for international students in China to learn and understand more about China. They believed that studying in Chinese universities not only meant studying Chinese language but also Chinese culture, politics, social system and so on. Nevertheless, some instructors were reluctant to teach international students and held bias against them, which was (very) disappointing and displeasing. The interviewees claimed that a university should be a place to learn knowledge instead of discriminating someone based on race, religion, or political opinion. Because of the bias from the instructors and maybe the university as well, the interviewees felt that their "learning boundary at the university gets smaller and smaller" (Ellen).

\subsubsection{Teacher-Student Relationship}

What also challenged the interviewees in study was the teacher-student relationship in China. As reported by all the interviewees, the teacher-student relationship in Korea was very good, but the Chinese instructors were generally hard to contact and were less friendly. Most instructors in Korea used SNS (Social Network Service) 
so that, whenever students had questions, they could be easily contacted, and vice versa. They sometimes had dinner together, shared ideas about study and life, and even drank alcohol together. In China, however, it seemed that a huge gap existed between instructors and students. The instructors could be reached only during office hours, during which students often had classes. Beyond the office hours, it was "(very) difficult" and "there is generally no chance to talk to the instructors" (Linda). Hence it was usually difficult for the Korean students to communicate and become familiar with their Chinese instructors. Therefore, Korean students often had difficulty knowing important notices or regulations issued by the university or the Chinese government timely, although there was a monitor for each class who served as a bridge between them and the instructors and the university.

As internationals from a different culture, Korean students often had their own working style and tended to do things in their own way. However, when they asked questions or did things in their culture-specific way, they were easily criticized by their instructors, which greatly blew off their confidence (Tim, male). As a result, most Korean students were afraid of asking Chinese instructors questions in university.

However, Korean students enjoyed a good relationship with international instructors in the university, who could be accessed through SNS and were willing to share with them ideas about schoolwork and life.

\subsection{Linguistic Challenges}

\subsubsection{Lack of an English-Speaking Environment}

As English majors, the majority of the participants' courses were conducted in English, which offered the participants chances to learn the literary style of English. Then, as English was not the official language or second language of China, English was not much used in daily life in the country, including Beijing, the biggest city and capital of the country. Consequently, there was little chance for the Korean participants to practice and use English in real life, let alone informal English. This was frustrating, because they could not improve English as they had expected or desired. To most of them, "the best way to learn a foreign language is to learn it in the native country" (Janice). Ellen did not think it a good choice to study English in Beijing also because too many Koreans were studying there, who liked to hang together.

Although there were various activities for students to practice and use English such as English corner, buddy program (language partners), English club, the Student Association for International Exchange, and parties for internationals, few participants ever attempted to make use of the resources. Or when a few tried to do so, they were rejected for certain reasons. For example, Cindy once applied for the school's buddy program, she was rejected because the program was only for native Chinese and native English speakers.

\subsubsection{Lack of a Chinese-Speaking Environment}

According to the participants, Korean students had difficulty developing their Chinese ability as well in the university. Since most of their courses were in English, they generally did not have much chance to speak Chinese in class. During their 4 years on campus, 9 of the 10 interviewees had only a maximum number of 5 courses taught in Chinese in total. Thus, their competence in formal Chinese did not improve, but remained at the high school level, or even fell down. As Janice recalled,

I came to China in high school. Because I had so much access to Chinese every day, I could speak and use Chinese well and even think in Chinese. Since I became an English major at this famous university, I don't need to use Chinese much. Consequently, my Chinese proficiency falls down. Although I have no difficulty having conversations with my Chinese instructors and Chinese friends, I cannot perform a high level of Chinese proficiency in either speaking or writing.

It was the same with Cindy and Ada.

Even though they were living in China, most participants reported that they did not have enough opportunities to speak/use Chinese in their daily life. They all confided that they used Korean instead because of the following reasons: 1) too many Korean students were studying in the same department. As reported by the participants, up to $80 \%$ of the English majors of the university were Koreans, which made it sufficient for them to communicate largely in their mother tongue, 2) the pervasive existence of the Internet enabled them to access whatever information they needed in their mother tongue, and 3) they lacked Chinese friends. Because they studied and lived separately from the local students, most Korean students of the university had little chance to become friends with local students. With few Chinese friends, the need to speak/use Chinese was understandably not strong. In addition, though quite a number of clubs and language programs such as language partners were available on campus, the interviewees maintained that they were mainly for English- and Chinese-speaking students and those non-natives and non-English-speaking international students were isolated from the programs. All these demotivated them to learn Chinese or to voluntarily use the language in their daily life. 
Meanwhile, all the participants were fully aware that if they wanted to be more competitive and advantageous in Korean enterprises after graduating from the university, they should be able to use Chinese as fluently as possible. They also acknowledged that it was their responsibility to learn Chinese well as international students studying in China. Thus Tim and Janice took Chinese lessons in a private language school in their fourth year on campus. Judy and Jane envied their Korean counterparts studying in other departments of the university, who shared classes with the locals and thus had several or even many Chinese friends. They wished they had the same choice and opportunity so that they could improve both formal and informal Chinese.

\subsubsection{Code-Switching between English and Chinese}

With Chinese as the second language and English as the foreign language, the informants had to face the problem of code-switching. For example, when Tara wanted to speak English, Chinese came out, and vice versa. In addition, English and Chinese words were sometimes confusing to them. For example, when Ellen needed to speak certain English words, she could only think of Chinese words, which happened many times. Seven interviewees attributed this to the lack of both English- and Chinese-learning environments which resulted in their low proficiency in the two languages. To Judy, language ability was much related to the language-using environment. During her four-year university life, both English- and Chinese-learning environments were very poor. She thus could not enhance her Chinese and English abilities to a higher level. Ultimately, she could not use the two languages freely at her will and had the code-switching problem when trying to use the two languages. Likewise, 4 other interviewees held the same idea.

\subsection{Cultural Challenges}

Even though both Korea and China are located in East Asia and embrace Confucianism, the two countries are different in many aspects, such as educational system, political system, interpersonal relationship, living and working styles. Thus, since they came to China, the informants had encountered a series of cultural challenges. The most striking shock reported by all the participants was that children, especially small children aged below 5 years, often peed or pooped in public, which was totally unacceptable in Korea. Bare-chested men walking on the street and crossing streets without following traffic orders were also shocking to the interviewees, followed by having too many bicycles on the street. As Jane narrated, "I have never expected to see so many bicycles on the road. And I have never thought that bicycles could cause traffic jams. But there are thousands of bicycles on the streets in Beijing, and hundreds of bicycles on campus. It is simply spectacular". If they could become used to so many bicycles and the jams caused by them, they found that some Chinese just left without saying any word after they started a bicycle accident. This was unbelievable and (very) uncomfortable (Cindy).

What was also unacceptable to the interviewees was that they had to take make-up lessons if there was a long holiday during the term in China. As Tim remarked, "we never have classes on holidays and weekends in Korea. However, in China, if we have a three- or five-day holiday, we have to take make-up lessons. This is really unpleasantly annoying".

In addition, what upset and puzzled them was that the university did not offer any course or lecture about how to get employed or how to find a job. As they reported, most Korean universities had courses about employment. However, they could access little information about how to get a job offer in the Chinese university. They could access little information about Korean enterprises either while they were in China. This, to them, was frustrating, because "getting a job offer is the biggest issue in a student's life and one of the purposes of trying hard to be admitted into a high-ranking university" (Jane). They hoped that the university would include them as well when lectures about employment were held for the locals instead of leaving them wander in the community.

In addition to the above-discussed challenges, both Janice and Amy voiced their concern that it was (very) dangerous for students to study abroad at an early stage who could not look after themselves yet, as did the participants of the present study. They thus suggested that these students should be accompanied by their parents or develop their ability to be independent and learn how to control themselves while studying abroad.

As discussed, the participants of the present study, as their peers in other studies (Berry \& Williams, 2004; Liu \& Cai, 2013; Nagy, 2008; Wilkinson, 1998b; Yang, 2012), confronted a series of academic, linguistic, and cultural challenges, though some challenges were specific to the context.

\section{Conclusions and Implications}

The present study explored the challenges Korean students had when studying in a Chinese university, which revealed that the Korean students were confronting a series of academic, linguistic and cultural challenges while studying in the university.

This finding means a lot to both the university and the Korean students studying in the university. As far as the 
university is concerned, it might be more helpful to the internationals if it re-examined and monitored its policies concerning international students. For example, since the university has been striving to become international, it is time to specify that internationals can share the same residentials or even rooms with the locals. By separating these two groups of students (e.g., in housing and classes), neither can understand and know better the other, severely affecting internationalization of the university and might even prevent the internationals from fitting into the local community. In addition, as the number of international students increases every year, it is time for the university to offer school policies, regulations, announcements, instructions, help and so on in different languages instead of only Chinese, especially in the dominant language(s) to the internationals, so that they can be well-informed of what is happening on campus or in a bigger community. Since Korean students accounted for the largest number of internationals in the university, it is beneficial to make Korean an important working or supplementary language on campus. This will help make Korean students feel at home and develop a sense of belonging to the university. Meanwhile, it is necessary to establish certain programs and/or clubs for international students to help them make friends, adapt to the study and life of the university, and fit in the local community or society.

As for Korean students, they need to do whatever they can to make the fullest use of the time while studying in the Chinese university. Even though most of the interviewees of the present study were encouraged to study in China by their parents, they should be responsible for their choices after deciding to come to China. Since language is the tool and carrier of everything, communication included, it is Korean students' as well as internationals' duty and responsibility to have a good command of Chinese if they want to fit in well in the university or in China. This means that they need to create opportunities to learn the language, which is so easy since they are in China, the native Chinese-speaking country. Nevertheless, it would be (rather) difficult if they choose to hang together with their co-nationals. As found in the present study, most interviewees chose to use Korean in their daily life, understandably their Chinese proficiency did not improve or even fell down after entering the university. If they had been more active to mix themselves with the local students or Chinese, the case would be much different. In order to better fit in the study and life in the university, it may be (more) useful if they could take the initiative to search information available on the school website, ask administrators and/or other people around (e.g., instructors and local students) rather than wait to be informed. Though not many programs for internationals were available on campus, internationals did have the choice of participating in various student associations on campus or establishing associations for international students. By doing these, they would have numerous opportunities to communicate, work, and even make friends with the local students. Consequently, they would be able to know and understand more about China and the Chinese culture. Nevertheless, if they distanced themselves from the locals by sticking to their co-nationals, as reported by the interviewees in the present study, they would naturally feel isolated and disappointed. More importantly, it is necessary for the internationals to be sure why they come to study in China, what they want to learn in China, what they expect of the university and themselves, and what they plan to do/achieve during and after finishing their study in university. With a clear goal and plan in mind, they may choose a more suitable university and discipline, and thus be more motivated to get involved in various school activities while studying in China and have a sense of belonging and accomplishment. Otherwise, they may feel demotivated, displeased, and dissatisfied with the university and themselves, as reported by most interviewees in the present study.

In a word, as more and more Chinese students choose to go abroad for higher education, more and more Chinese universities are also striving to recruit more and more international students. Being international means being open, multicultural, multilingual, and tolerant. Hence, Chinese universities which aim to become international had better take into consideration the internationals' needs, feelings, expectations, cultural backgrounds, living styles and so on that are different from Chinese before and after welcoming them into campus. Only by doing something really useful such as orientation lectures, programs for international students, and offering them open choices for accommodation and courses can it virtually help international students to adapt well to the study and life in the university. When necessary, it may also be useful to use the language of at least the predominant internationals on campus as the working language. These methods will help internationals feel respected, cared, and develop a sense of belonging, which can motivate them to learn more, Chinese and the Chinese culture included. Consequently, the local students can know more about the internationals and their cultures as well. Similarly, as internationals, it is necessary for them to become (more) prepared for the life and study in China prior to their sojourn, such as knowing more about how Chinese universities work, how Chinese live and study, and so on, as suggested in Liu and Cai (2013). It is also helpful for them keep in mind their purpose and actively participate in various activities organized by the university and/or the local community when studying in China. Only in this way can they learn what they want and achieve the real aim of international education-knowing more about China and the Chinese culture. 
If both Chinese universities and internationals try their best to become really international, it will be a win-win for both.

\section{Acknowledgement}

This work was supported by 2014 Asia Research Center in Tsinghua University.

\section{References}

Allen, H. W. (2010). Language-learning motivation during short-term study abroad: an activity theory perspective. Foreign Language Annals, 43(1), 27-49.

Bataller, R. (2010). Making a request for a service in Spanish: pragmatic development in the study abroad setting. Foreign Language Annals, 43(1), 160-175.

Berry, R. S. Y., \& Williams, M. (2004). Difficulties experienced by Hong Kong Chinese ESL learners at an independent school in the United Kingdom. Journal of Language and Social Psychology, 23, 118-134.

Cai, W., Li, X., \& Liu, M. (2013). Academic and linguistic gains during a semester long study abroad: A Cohort Case Study. Studies in Second Language Learning and Teaching, 3(4), 505-522.

Chen, D. (2007). Changes in social distance among American undergraduate students participating in a study abroad program in China (Unpublished Ph.D Dissertation). University of North Texas, USA.

Cohen, A. D., \& Shively, R. L. (2007). Acquisition of requests and apologies in Spanish and French: Impact of study abroad and strategy-building intervention. The Modern Language Journal, 91(2), 189-212.

Dewey, D. P. (2004). A comparison of reading development by learners of Japanese in intensive domestic immersion and study abroad contexts. SSLA, 26, 303-327.

Hernández, T. A. (2010). The relationship among motivation, interaction, and the development of second language oral proficiency in a study-abroad context. The Modern Language Journal, 94(4), 600-617.

Jackson, J. (2004). Language and cultural immersion: an ethnographic case study. Regional Language Center Journal, 35(3), 261-279.

Jackson, J. (2011). Cultivating cosmopolitan, intercultural citizenship through critical reflection and international, experiential learning. Language and Intercultural Communication, 11(2), 80-96.

Koester, J. (1986). A profile of foreign language majors who work, study, and travel abroad. The Modern Language Journal, 70(1), 21-27.

Lafford, B. A. (2004). The effect of the context of learning on the use of communication strategies by learners of Spanish as a second language. Studies in Second Language Acquisition, 26, 201-225.

Lindseth, M. U. (2010). The development of oral proficiency during a semester in Germany. Foreign Language Annals, 43(2), 246-268.

Liu, M., \& Cai, W. (2013). Expectations of and Concerns about Semester-long Study Abroad: A Case Study. International Journal of Education \& Literacy Studies, 1(1), 72-81.

Llanes, A., \& Muñoz, C. (2009). A short stay abroad: Does it make a difference? System, 37, 353-365.

Martinsen, R. A. (2011). Predicting changes in cultural sensitivity among students of Spanish during short-term study abroad. Hispania, 94(1), 121-141.

Milton, J., \& Meara, P. (1995). How periods abroad affect vocabulary growth in a foreign language. ITL Review of Applied Linguistics, 17-34, 107-108.

Nagy, B. C. (2008): Linguistic and socio-cultural outcomes of the Au Pair experience in the United Kingdom. Language and Intercultural Communication, 8(3), 172-191.

Pérez-Vidal, C., \& Juan-Garau, M. (2011). The effect of context and input conditions on oral and written development: A study abroad perspective. IRAL, 49, 157-185.

Sasaki, M. (2007). Effects of study-abroad experiences on EFL writers: A multiple-data analysis. The Modern Language Journal, 91(4), 602-620.

Segalowitz, N., \& Freed, B. F. (2004). Context, contact, and cognition in oral fluency acquisition: Learning Spanish in at home and study abroad contexts. Studies in Second Language Acquisition, 26, 173-199.

Taguchi, N. (2008). Cognition, language contact, and the development of pragmatic comprehension in a study-abroad context. Language Learning, 58(1), 33-71. 
Taillefer, G. F. (2005). Foreign language reading and study abroad: Cross-cultural and cross-linguistic questions. The Modern Language Journal, 89(4), 503-528.

Trenchs-Parera, M. (2009). Effects of formal instruction and a stay abroad on the acquisition of native-like oral fluency. The Canadian Modern Language Review, 65(3), 365-393.

Ward, C., \& Kennedy, A. (1994). Acculturation strategies, psychological adjustment, and sociocultural competence during cross-cultural transitions. International Journal of Intercultural Relations, 18, 329-343.

Wilkinson, S. (1998a). Study abroad from the participants' perspective: A challenge to common beliefs. Foreign Language Annals, 31(1), 23-39.

Wilkinson, S. (1998b). On the nature of immersion during study abroad: Some participant perspectives. Frontiers: The Interdisciplinary Journal of SA, 4, 121-138.

Xia, S. (2009). Are they ready to participate? East Asian students' acquisition of verbal participation in American classrooms. Issues in Applied Linguistics, 17(2), 137-157.

$\mathrm{Xu}$, W., Case, R. E., \& Wang, Y. (2009). Pragmatic and grammatical competence, length of residence, and overall L2 proficiency. System, 37, 205-216.

Yang, L. (2012). The impact of a study abroad program in China on its participants' attitudes towards China (Unpublished Ph.D Dissertation). University of Minnesota, USA.

Yu, B. (2010). Learning Chinese abroad: The role of language attitudes and motivation in the adaptation of international students in China. Journal of Multilingual and Multicultural Development, 31(3), 301-321.

\section{Copyrights}

Copyright for this article is retained by the author(s), with first publication rights granted to the journal.

This is an open-access article distributed under the terms and conditions of the Creative Commons Attribution license (http://creativecommons.org/licenses/by/3.0/). 